\title{
Building communities. Presenting a model of community formation and organizational complexity in southwestern Anatolia.
}

\author{
Daems, Dries \\ Sagalassos Archaeological Research Project - KU Leuven \\ Suna \& Inan Kıraç Research Centre for Mediterranean Civilizations
}

\begin{abstract}
In this paper, a model of community formation and organizational complexity is presented, focusing on the fundamental role of social interactions and information transmission for the development of complex social organisation. The model combines several approaches in complex systems thinking which has garnered increasing attention in archaeology. It is then outlined how this conceptual model can be applied in archaeology. In the absence of direct observations of constituent social interactions, archaeologists study the past through material remnants found in the archaeological record. People used their material surroundings to shape, structure and guide social interactions and practices in various ways. The presented framework shows how dynamics of social organisation and community formation can be inferred from these material remains. The model is applied on a case study of two communities, Sagalassos and Düzen Tepe, located in southwestern Anatolia during late Achaemenid to middle Hellenistic times (fifth to second centuries BCE). It is suggested that constituent interactions and practices can be linked to the markedly different forms of organizational structures and material surroundings attested in both communities. The case study illustrates how the presented model can help understand trajectories of socio-political structures and organizational complexity on a community level.
\end{abstract}

Keywords: Social complexity, community formation, Sagalassos, Anatolian archaeology, social interaction, organizational complexity.

Highlights:

- Social interaction and information transmission generate complex social organisation.

- People use material surroundings to shape and transmit information.

- Complex systems thinking can help understand organizational structures in the past.

- Urbanization entails pockets of interaction shaped by material surroundings.

\section{Introduction}

In this paper, we discuss processes of community formation and the development of organizational structures in the past. The approach presented here draws from the integration of complex systems thinking with archaeological and social theory. Emerging in the 1970s out of fields such as biology, chemistry, physics, mathematics, general systems theory and cybernetics, complex systems thinking emphasizes non-deterministic and non-linear behaviour, interactive interdependencies among system components, feedback loops, and complex behaviour emerging from simple interactions (Cabrera et al. 2008; Mitchell 2009). The study of complex social systems in particular focuses on constituent social interactions generating complex organizational structures (Freeberg et al. 2012). Complex systems theory has, in recent years, pervaded a wide range of disciplines, including archaeology (Bentley and Maschner 2003). It particularly makes use of formal methodological tools such as computational modelling and network analysis. In this paper, however, a conceptual model based on some theoretical core tenets of complex systems thinking, such as self-organization, emergence, and information processing will be presented.

Through the use of concepts derived from complex systems thinking, the model presented here will allow us to study social dynamics related to community formation and the development of complex organizational structures through a new lens, focusing on core properties such as social interaction and information transmission. The model starts from the level of information transmission through social 
interactions and details how increased face-to-face interactions can result in emergent societal changes on a community level, expressed in processes of community formation, socio-economic growth, and scalar stress. To account for the peculiar nature of the archaeological record as main evidence for the past societies that we study, we outline how this conceptual model can be applied in an archaeological context by focusing on the transmission of information through material surroundings and objects.

The potential of this model and conceptual framework will be shown through a preliminary case study. It should be noted that this paper only constitutes a first tentative step in the application of this approach. Here, we will focus in some detail on two communities, Sagalassos and Düzen Tepe, located in southwestern Anatolia during late Achaemenid to middle Hellenistic times (fifth to second centuries BCE). Future studies will include more data points and case studies in order to fully demonstrate the utility and potential of the approach, outlined here. The present case study consists of a detailed evaluation of the archaeological data available for both communities in this period. By carefully evaluating and comparing the material remains from both communities, we will show how the presented model can help understand these material remains to infer knowledge regarding processes of community formation and the dialectic nature of the interaction between both communities. Finally, we suggest a possible scenario of community formation by linking these micro-level dynamics to the macro-level historical framework of the Hellenistic period.

\section{A model of community formation and organizational complexity}

For most of our history, humans sought to live together in social groups of varying sizes and configurations. In many of these configurations, kinship played an important part. Yet, oftentimes what constitutes a 'community' goes beyond immediate kin relations, and also includes matters of culture, identity and social cohesion. A community is dynamically created by socially constituted and contingent social structures (Varien and Potter 2008). Communities are therefore strongly predicated upon (social) interactions as their major constituent elements (Cohen 1985, p. 17).

As a starting point, we can use a definition offered by Canuto and Yaeger, who stated that a community is "an ever-emergent social institution that generates and is generated by supra-household interactions that are structured and synchronized by a set of places within a particular span of time. Daily interactions rely on and, in turn, develop shared premises or understandings, which can be mobilized in the development of common community identities" (Canuto and Yaeger 2000, p. 5). Steidl (2018) outlined in her recent Ph.D. dissertation a number of essential characteristics of community that can be stressed here:1) they are shaped by daily interactions, 2) they often have a spatial component but are not necessarily confined to a shared space, 3) they are multiple, layered and nested, 4) they act as sites of learning and information transmission, thus functioning as communities of practice, 5) they are loci of shared values and ideas but need not necessarily be actively acknowledged or perceived.

Community formation is also inherently related to matters of identity and self-definition of in-group members (Steidl 2018). However, in this paper we will not focus on community identities, but rather take a practice-based approach focusing on interaction and cooperation. Community formation, in this sense, essentially entails matters of cooperation between individuals (Axelrod 1984; Blanton and Fargher 2016). Cooperation is the central element for developing collective action measures. Collective action is considered here in the broad sense as every measure used to mobilize a group of people towards a common goal as part of wider processes of community formation. This is a more extensive approach than that used in collective action theory, which focuses more specifically on the dialectic relationship between social actors and the actions of rulers as driver of decision-making processes (Ostrom 2009). In general, two major modes of consensus-seeking can be employed within a community to stimulate cooperation and coordination on a collective level (Baronchelli 2017). These centralized institutions operating in a top-down manner, and spontaneous consensus generated bottom-up through interactions between agents. The reasons why people might venture into collective endeavours are legion. The principal causal factors for developing social organization are oftentimes related to the material conditions of human existence, i.e. demographical, ecological, technological, and economic factors, as these relate to the most basic human needs in production of subsistence and the reproduction of human life (Sanderson 1999). Even if we can consider the full spectrum of community formation dynamics to be more extensive than this, for example including also ideological factors, collective action driven by 
these material conditions constitutes the basic platform for such dynamics to develop, as a common plane upon which shared, day-to-day activities, interactions, and socialization take place (Smejda and Baumanova 2015, p. 53).

At the same time, community formation cannot be fully reduced to aggregation of social interactions and practices (Blau 1964). Human societies should rather be considered as complex systems where social organization emerges from the social interactions that are its constituent building blocks. As a starting definition, it can be stated that "complex social systems are those in which individuals frequently interact in many different contexts with many different individuals, and often repeatedly interact with many of the same individuals over time" (Freeberg et al. 2012, p. 1787). Social interaction occurs when two or more people 'encounter' each other, that is, create an episode of mutual awareness supplemented by communication (Turner 2003, p. 4). We consider here communication in a broad sense as any exchange of information (Castellani and Hafferty 2009, p. 38). Information transmission is not merely a "like-for-like" process, but has important multiplicative effects. This suggests that the origins of increasing social complexity lie in growing community sizes and an associated exponential increase in (potential) structural social interactions (Dubreuil 2010; Fletcher 1995). Neither is linearly related, but rather they are mediated by degree of connectivity and integration in governmental and institutional structures (Feinman 2011).

Increased spatial proximity associated with community formation and urbanisation induces improvements in flows of information, thus generating increasing returns to scale, both on a social and economic plane (Bettencourt 2013; Ortman et al. 2015, 2016; Smith 2019). When a greater amount of people is more closely concentrated, social learning and knowledge transfers can take place more efficiently. Additionally, knowledgeable agents are more likely to be present. Interactions can take place more frequently in highly clustered networks and are affected by more rapid feedback loops, thus decreasing lag time in the transfer of information.

At the same time, cognitive constraints on information processing capacities impose limits on information transmission (Dunbar 1993; Freeberg et al. 2012). Human groups, however, can circumvent these biological limits through the development of social organization in order to better process socially transmitted information and take collective decisions more effectively (Auban et al. 2013, p. 56). This process should not be seen as an inevitable trajectory of organizational development in increasingly complex societies, as was prevalent in earlier works on social evolution (Service 1962). Cioffi-Revilla (2005) argued in an algorithmically formalized model of socio-political complexity development, that whether or not complex organizational structures develop and are sustained, depends on a sequence of steps in a recursive loop of signal detection, information-processing, and problem-solving, resulting in either successful or failed adaptation and development of social organization. The loop is induced by a social group reacting to situational events, which can be highly various in nature, including stresses and opportunities, endogenous and exogenous processes, social or physical in nature, and human or environmental induced. The loop consists of a dual trajectory, with a 'fast process' of crisis and opportunistic decision-making through collective action feeding a 'slow' process of socio-political development or decay.

The theoretical approaches discussed in this part - the multiplicative effects of social interaction, emergent properties of community formation, limits to information-processing, and recursive loop of complexity development - are the core components of the archaeological application outlined in the following parts. We will discuss how material remains - mostly architectural structures and associated material culture - from two communities in southwest Anatolia - Sagalassos and Düzen Tepe - can be interpreted in light of processes of community formation and the development of organizational complexity. We will specifically highlight how this framework can help us understand the dialectic relation between both communities, and focus on the genesis of urban communities through the interactions between micro-level community formation processes and macro-level polities.

\section{But where does the archaeology come in?}

The model highlighted above can be used as a general framework to trace processes of community formation and organizational complexity. How can we now relate this general conceptual framework to the archaeological record, given the lack of direct observations of constituent practices, interactions and 
activities of social organization in the past? In other words, how to identify communities and trace processes of community formation in material remains (Steidl 2018).

It should be stressed that all actions and interactions inherently have a temporal, spatial, and social dimension. They take place at a given time, at a given place, and within a certain social framework. For example, a settlement is inhabited at a specific time and place, and can be considered to reflect the actions and practices of the community it housed (Robb 2007; Smith 2003). Others have questioned this approach, suggesting that community space almost inevitably extended beyond that of the site as typically defined (Kolb and Snead 1997). However, whether or not both necessarily fully converge is not the point of interest here. Instead, it is important to stress that the material remains intrinsically can be correlated with the actions of the society or community producing it. In this sense, any settlement can be considered as a 'pocket of interaction' where, given their generally higher population numbers and increased population density, an increased amount of social interactions occurs in settlements compared to the surrounding areas (Southall 1973, p. 6). The settlement can therefore be considered a general approximation of the spatial delineation of the densest parts of the network of interaction in a given community.

Giddens (1986, p. 110) also considered settlements as containers of social interactions and actions in his concept of 'locale', defined as the temporally and spatially defined context in which social practices are manifested. Spatial and temporal configurations are essential both as external context and internal structuration of these practices. This entails not merely the physical properties of space in a Euclidean sense but also its material context and how space is used for human activities and provides for the context of social life. Locales can be located within any spatial setting, a room, a house, a street corner, a town, a city, etc. Spatial properties and performance of social practices can also be combined through the concept of 'place', defined as 'lived space', ascribing meanings, identities and memories that actively shape people's daily practices and experiences (Feld and Basso 1996; Low and Lawrence-Zuniga 2003; Rodman 1992). Places offer spatial contexts for people to orient themselves and act within culturally constituted landscapes based on heterogeneous social knowledge and experience (Robb 2007, p. 9). Through the concepts of locale and place, a mutually constituting relationship between settlement form and the actions and interactions of heterogeneous individuals, groups, and institutions, each with their own motivations and identities can be proposed (Fisher and Creekmore 2014, p. 1).

This framework allows archaeologists to analyse material environments, not only as invariant contexts for social action and interaction, but also as reflecting at heart the nature and intensity of these processes, and thus providing a way to connect the archaeological record with the dynamics of the society which produced it. To this end, we will explore here Rapoport's (1988, 1990, 2006) model of material environment-behaviour interactions. He distinguishes three levels of material communication and information transfers: 1) Low-level meaning focusing on mnemonic cues of identifying the uses for which certain material settings are intended, enabling users of a certain place to behave and act appropriately and predictably; 2) middle-level meaning communicating deliberate statements about identity, status, wealth, power, and other traits; 3) high-level meaning as a symbolic representation that only exists within the context of a specific cultural and religious system. Not all three levels can or will necessarily be distinguished in any particular instance of the archaeological record. Moreover, in absence of written sources it will often be difficult to comprehensibly trace high-level meanings.

Still, the approach allows a clear pathway to move from material settings to social practices in the past. Moreover, it also allows for material objects to be integrated in this overall perspective. Through specific instances of use, objects are 'enchained' in interlinked sets that are structured spatially and temporally, thus creating distinct and circumscribed locations pulling together sets of material linkages to constitute social practices in which these objects are 'proper' to be used (Lucas 2012). If the iteration of use is sufficiently recurrent and extensive, stabilized networks of action are formed, where the interactions between interrelated sets of enchained objects and the circumscribed spaces in which they are embedded, create socially meaningful contexts (Fletcher 1995).

Of course, human action need not always follow prescribed rules. Individual engagement with material culture within a technological system, both from a production and consumption point, inevitably results in variability and diversity (Page 2010). In any given social context, this variability can carry a range of social meanings. While variability is created through the productive side of the chaine opératoire, its consolidation lies in visual recognition, or lack thereof, by others within the community (Kohring et al. 
2007, p. 103). Within the social arena of a given community, a certain leeway exists for both producers and consumers to manipulate the material culture to their disposal and the meanings they carry. In essence, different 'stakeholders' involved in all steps of the operational sequence of production and use of material goods (most notably producers, traders, and consumers) enter a complex negotiation of meaning associated with particular objects. In this sense, material culture itself should be considered as carrying certain messages of meaning and therefore as transmitting information.

This is nothing new, Clarke (1968) already considered material culture as inherently carrying and transmitting information. More recently, it has been suggested that diversity in material culture can be directly linked to its functionality as an information transmitter through its role as regulator in managing cognitive limits to information processing (Kohler et al. 2004; Nelson et al. 2011). Homogeneity (i.e. low diversity) in material culture can be linked to overall strategies of social conformity by inducing conformist behaviour, thus facilitating intragroup cooperation as a way to reduce scalar stress in consensual decision making by establishing a degree of social cohesiveness (Hodder 1979; Johnson 1982). More homogeneous material culture is indeed commonly associated with increases in group size, density, or scale (Johnson 1982; Kohler et al. 2004).

Information is thus contained in the physical and material world around us, and as such inherently deposited in the objects and structures that provide the setting for human life (Hidalgo 2015). These objects allow people to communicate messages, coordinate our social and professional activities, and transmit knowledge and knowhow as the necessary 'software' that allow information processing to take place (Hidalgo 2015, p. xviii). As such, objects are embodiments of knowledge and knowhow, integrated in social and economic networks. Information is thus stored and accumulated in social and economic networks of people, places and objects. The nature and composition of a community' social and economic networks is therefore of primordial importance for its subsequent development. Let us now illustrate the theoretical and conceptual framework highlighted so far with a case study. The case study will focus specifically on the origin of community formation and initial development of organizational complexity at two settlements, Sagalassos and Düzen Tepe (southwest Anatolia), during late Achaemenid to middle Hellenistic times (fifth to second centuries BCE).

At the beginning of this period, most of Anatolia was firmly under control of the Achaemenid Persians, until the conquests of Alexander the Great in 334 BCE. After the death of Alexander, his generals quarrelled over the remains of his empire. After a period of internal struggles, the Seleucids emerged as the leading faction in Anatolia for most of the third and early second centuries BCE. However, their hold on Anatolia was never fully secure, with the Ptolemies holding extensive portions of the coastal areas in the southwest, and a number of (semi-)independent kingdoms such as Pergamon and Pontus controlling large areas in the north. It is against this larger background of competing royal dynasties that the communities discussed here emerged and developed. While it is difficult to link the impact of macro scale events directly onto micro scale processes, as we will see, overarching polities did sometimes exercise significant influence over local dynamics as communities reacted upon the stimuli and policies of these macro level polities.

\section{Community formation and social organization on the ground.}

\section{Düzen Tepe}

The site at Düzen Tepe is located on a plateau at the foot of Mount Zencirli, overlooking central parts of the Ağlasun valley and the valley of Yeşilbaşköy (Figure 1). The outlines of the settlement were traced through a combination of remote sensing, and geophysical, topographical and archaeological surveys. Scattered structures were identified all over the plateau across an area of almost $75 \mathrm{ha}$, with a clear settlement nucleus of about 13ha. Most evidence for the dating of habitation at the site has been derived from pottery material, suggesting a general occupation period between the late fifth and second centuries BCE (Daems et al. 2017). Other finds such as a handful of glass fragments and coins dated to the fourth and third centuries BCE corroborated this general date. However, little evidence for further chronological relief or resolution within this general chronological bracket is available, which makes it difficult to temporally relate individual structures within the settlement. 


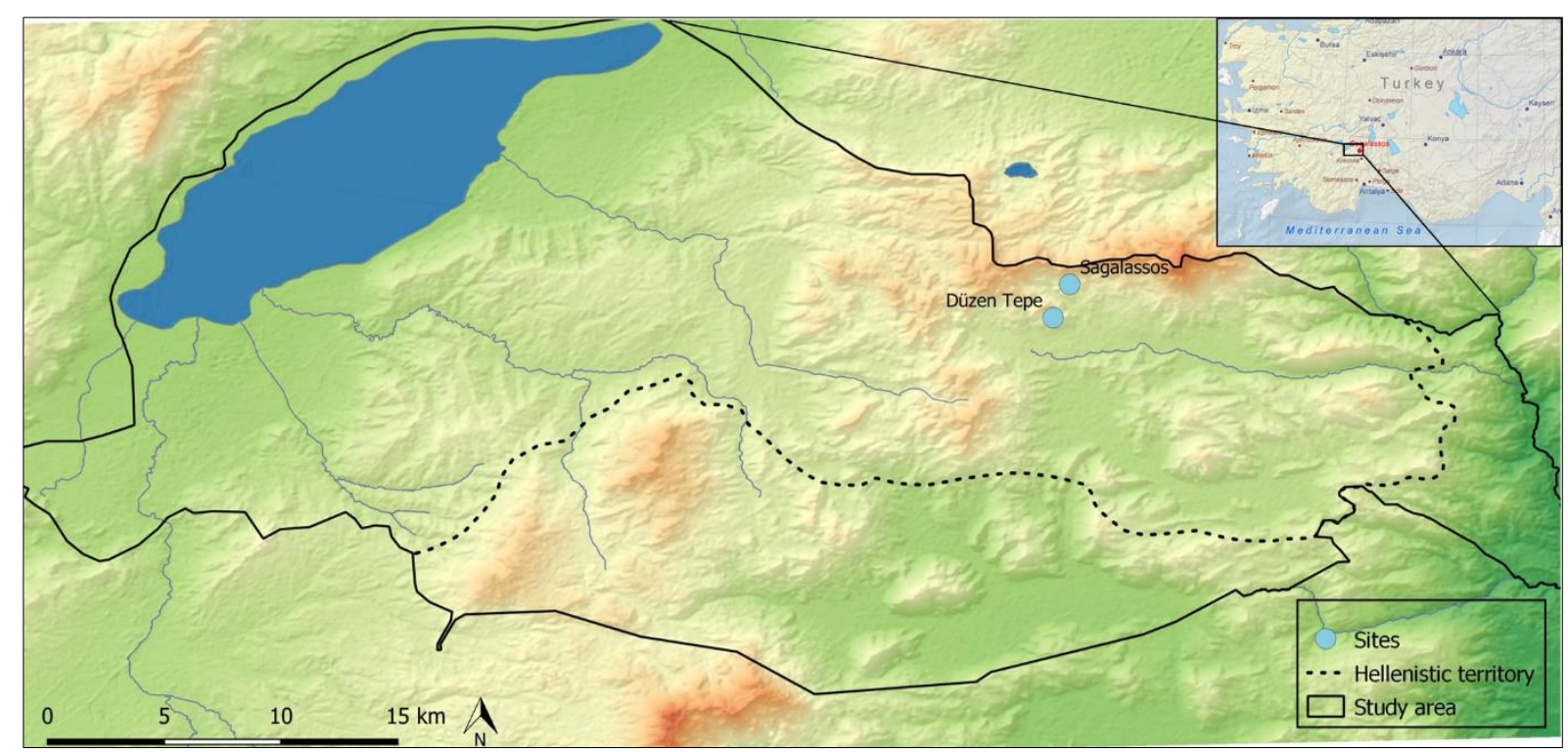

Figure 1: Location of Düzen Tepe and Sagalassos within the study area of the Sagalassos Project and location of Sagalassos (red) in Anatolia (made by the author).

Despite its relatively large size, Düzen Tepe was a largely rural community of about 1000 people, consisting mainly of farmers working in a smallholders-based subsistence system (Cleymans et al. In Preparation) and locally-oriented economic system (Daems and Poblome 2016) with little indications for social stratification. In such communities, social life was likely for a large part oriented towards the household or other family-based social units. The generally disordered settlement layout of the village shows no clear indications for a centralized or public locus onto which communal life could have been systematically oriented. However, many structures appear to follow more or less a common NE/SW orientation (Figure 2).

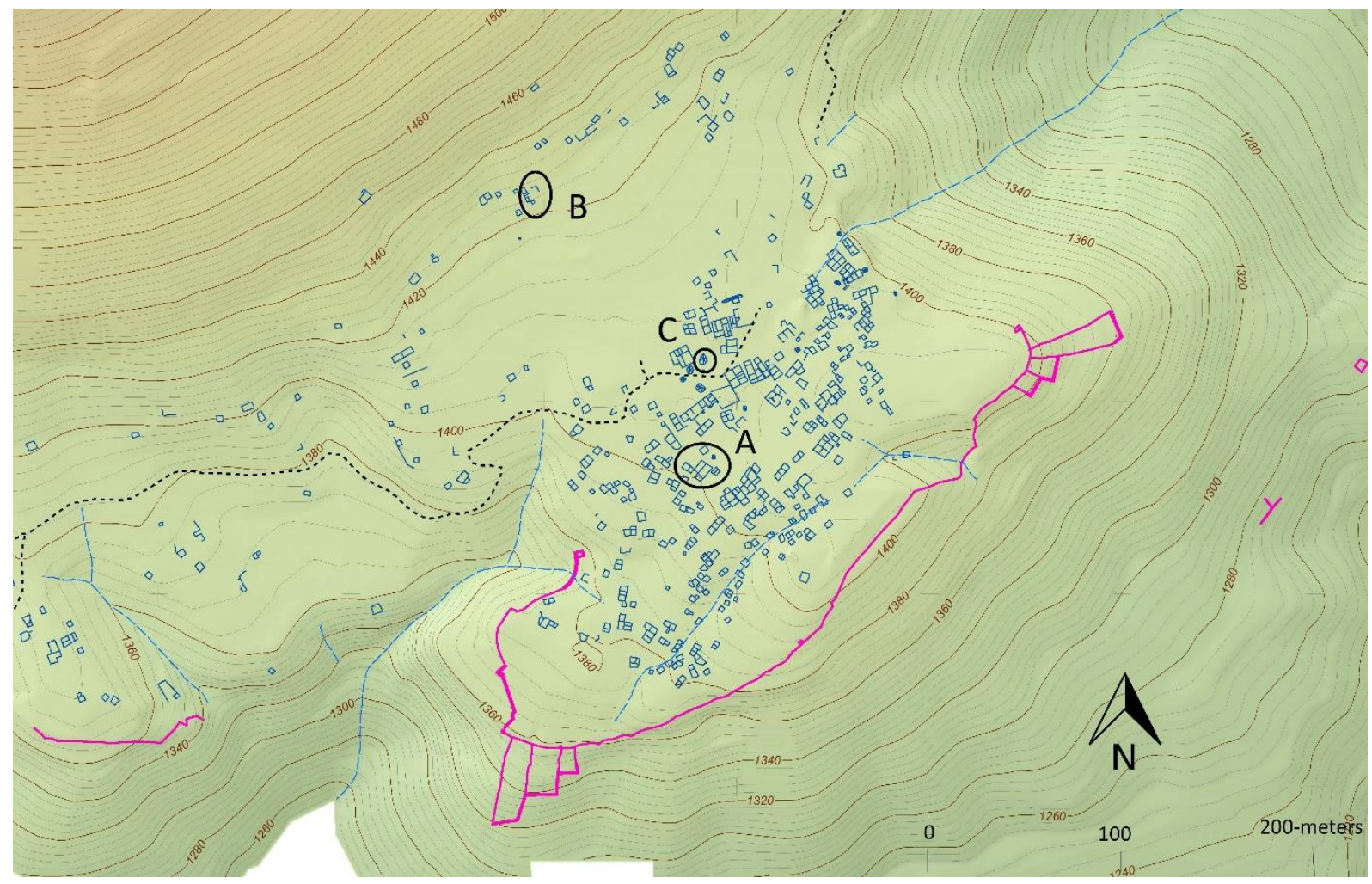

Figure 2: Settlement plan of Düzen Tepe with settlement structures (blue) and fortifications (purple) and indication of buildings discussed in text (A-B-C). Contour intervals are 20m (@) Sagalassos Project). 
Only one domestic structure was excavated so far, the so-called 'Courtyard Building' (CYB) (A on Figure 2). Of this structure, $265 \times 5 \mathrm{~m}$ sectors were excavated, exposing an area of over $650 \mathrm{~m}^{2}$ centred on a cluster of nine rooms that were oriented along an L-shaped open space $\left(80 \mathrm{~m}^{2}\right)$, most likely a central hallway or courtyard (hence the name of the building). The structural remains consist of in situ preserved stone foundations of about 50 to $75 \mathrm{~cm}$ wide, which provided the foundations for the rest of the structure which is badly preserved but possibly consisted of mudbrick or wattle-and-daub. The foundations consisted of irregular limestone rubble, most likely field stones collected from the surface of the immediate surroundings of the site. No traces of a mortar binder were found in any of the foundations and they were built directly onto the bedrock, incorporating any height differences on the terrain. Most spaces are roughly square or rectangular in shape, ranging between $11 \mathrm{~m}^{2}$ (Room B) and $42 \mathrm{~m}^{2}$ (Room C). Based on the observation that some of the rooms have abutting rather than shared walls, it has been suggested that the structure was not originally planned as one single building, but rather that several rooms were added in different phases (Vyncke and Waelkens 2015, p. 164).

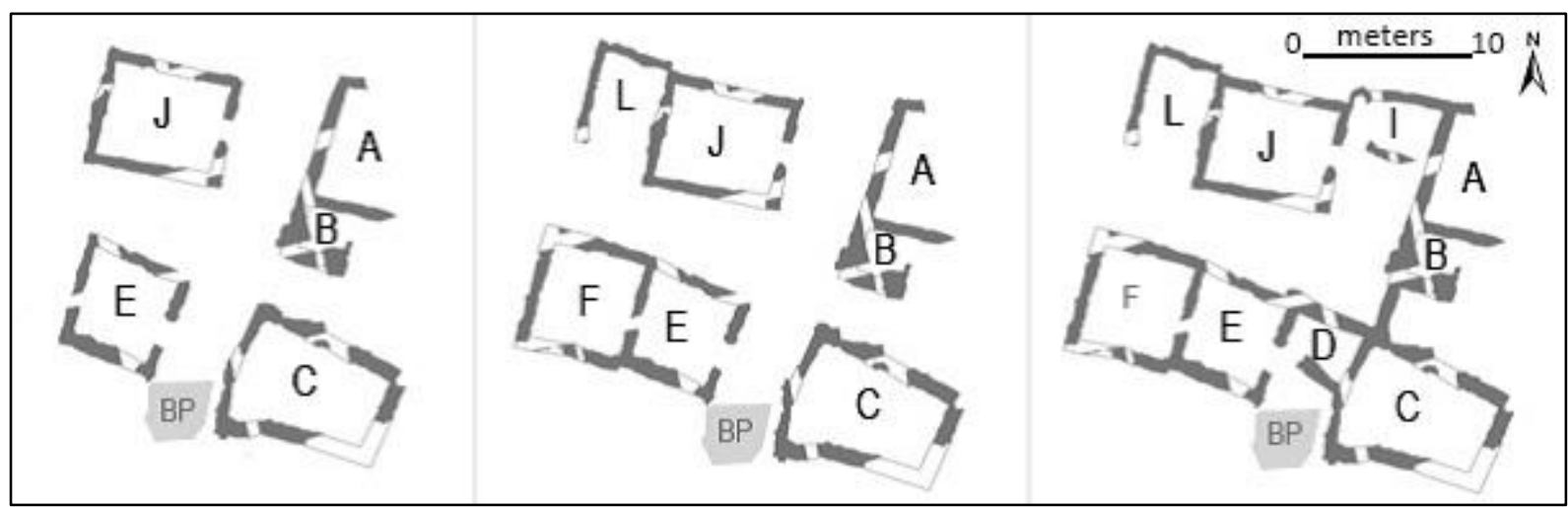

Figure 3: Different building phases of the Courtyard Building (the letters indicate different rooms) (Vyncke 2013, p. 149).

Some indications such as the lack of doorways between certain rooms and the discontinuous wall trajectories of certain rooms, indeed suggest that at least parts of the building may not have been part of the original building phase. Consequently, the L-shaped central space may only have been a coincidental result of successive building activities, although it is remarkable that the central cluster of the building can be subdivided in two sequences of rooms (L-J-I and F-E-D) each bordering an apparent open space. Although whether this was really the case for the space south of the building is unclear given the limits of the excavated zone. Possibly this sequence was mirrored at the eastern side as well in the sequence of rooms A-B (and C?). It is unclear whether these room sequences represented three distinct clusters, for example centred around different individual households, or whether the entire structure belonged together. The fact that the rooms within each of the sequences only open up towards the different open spaces, but not towards each other, favours the first hypothesis. Little 'depth' in room access could be observed, with quick access from the outside possible for most rooms. Only in room F, no clear doorways have been observed in the outer walls, suggesting it had no direct access from the outside, but was only accessible through room $\mathrm{E}$, unless the entrance was located in the unexcavated axis of the Wheeler box-grid in the southwestern and northwestern corners of the room (see infra).

Slightly towards the north of CYB, a single-room structure was found with three roughly circular holes with a diameter between $0.25-0.50 \mathrm{~m}$, dug out in the bedrock (Figure 4). The remarkable amount of fragments of large storage vessels found here suggests that these may have been used to fix pithoi vessels in the floor bed (Vyncke and Waelkens 2015, p. 166). Additionally, a variety of objects was found, including a loom-weight, spindle whorl, a fibula, an arrow head, some coins and astragali, as well as some amounts of metallurgical production waste and undefined metal objects. This isolated structure can likely be interpreted as a storage room. Whether it can be associated with the CYB remains unclear. 


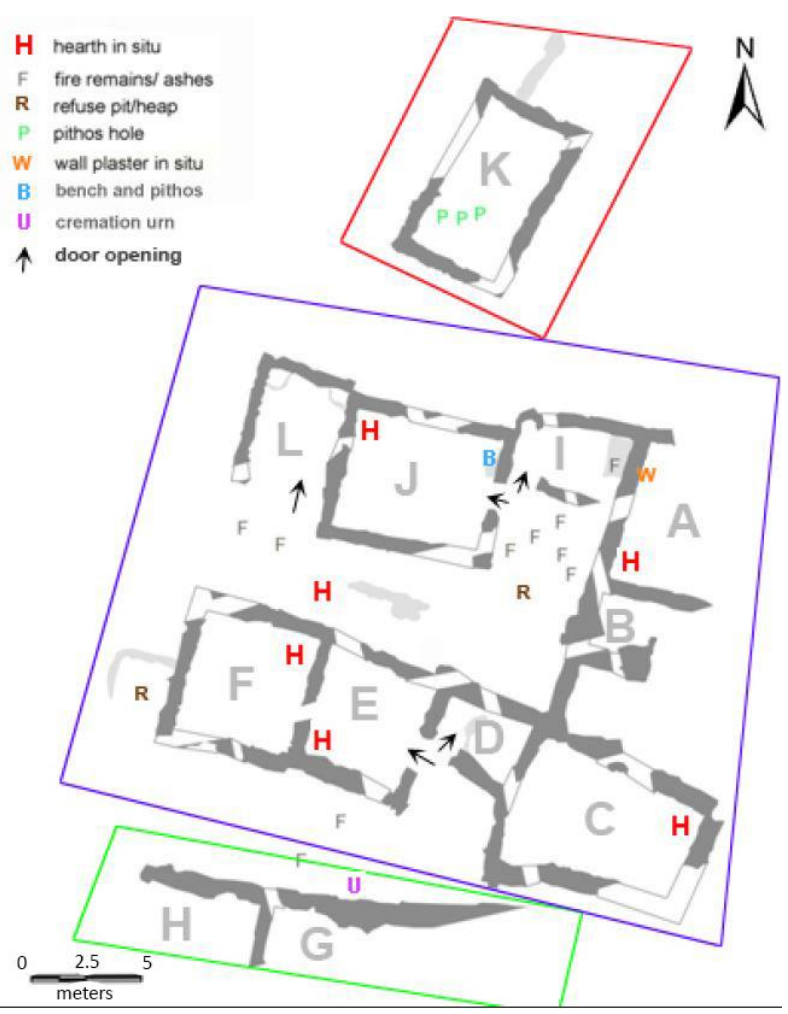

Figure 4: Features attested during the excavation fo the Courtyard Building. The coloured rectangles indicate different units within the excation (main structure in blue, storage room in red and other stucture in green) (Vyncke 2013, p. 138).

In the open space south of the CYB, a square pit ("Bedrock Pit" or BP on Figure 3) 3x3m wide and 0.5 to $0.6 \mathrm{~m}$ deep was cut into the bedrock. Its relation to the structure remains unclear. In its northern side, a triangular niche containing burned sediments was cut out. In an occupation layer at the edge of the pit, the remains of a cremation urn were found. The relationship between this burial, the pit and the building to the north remains unclear. The deepest layer of the pit contained remains of a plastered hearth and could have been the original occupation layer, covered by a possible destruction layer and two postoccupational layers (Vyncke 2013, p. 149-150). Especially for the latter, this interpretation should be considered highly tentative as, although huge amounts of material have been collected from these contexts, the finds provide little indication as to the nature, chronology or functionality of the pit. Given that the opening of rooms D and F open towards the pit, it can be suggested that that the pit was not present at the time of occupation of the house and therefore possibly testimony of an earlier phase of settlement. Vyncke (2013, p. 150) tentatively suggested an interpretation as remains of a pit-building pre-dating the construction of the CYB (Vyncke 2013, p. 150). However, no indications could be found in the pottery material collected from this bedrock pit that this would have been markedly older, or in any other way different for that matter, than the CYB, as both generally yielded the same types of material.

Houses such as CYB likely constituted the main places where life at Düzen Tepe took place. These vernacular architectural structures provided the locale for social practices related to subsistence, reproduction, and other basic spheres of social life, such as food processing and cooking, storage, production, habitation, leisure, and discard. In rooms A, C, F and J, as well as the northern courtyard, a series of features consisting of a horizontal layer of fired clay were found, most likely hearths. It is interesting to note that all hearths found inside were located close to the corner, suggesting a cooking function instead of heating (Vyncke et al. 2011, p. 2290). Additionally, a number of fire contexts lacking the distinct layer of fired clay have been noted as well, both inside and outside the rooms. Likely these can be associated with the use of portable braziers, as a few examples of such objects were attested in the excavations at Düzen Tepe, and should rather be associated with heating practices.

The presence of a refuse pit in the central courtyard and outside room F, containing small animal bones and large faunal remains, provides additional evidence for food processing activities taking place within the confines of the building. The central courtyards along which the rooms were oriented would likely 
have provided a central focus for many household activities, including outside cooking in the times of year when the weather would have permitted it. At the same time, the centrality of the courtyard was essential in tying different architectural elements together into a single unit because of the low amount of inter-room connections. As a result, the courtyard retained a high control value in monitoring social life. In the northeast corner of Room I, a pebble floor $(1.9 \mathrm{x} 0.8 \mathrm{~m})$ was discovered on top of the ground level, consisting of small limestone pebbles. It has been suggested this area constituted a working area, with the pebble surface possibly serving to provide a clean area free from floor sediments (Vyncke 2013, p. 144). Except for a burnt sediment covering the pebble surface at the southern side, possibly as a result of fire used here for certain activities, no further indications as to the exact nature of this space have been attested. We have no other evidence to corroborate the tentative suggestion of Vyncke (2013, p. 144) that it may have served a religious function, for example as a (house-) shrine.

To assess in more detail the potential uses of the overall structure, floor sediments of room $F$ were sampled for chemical analysis to identify traces of anthropogenic residues and provide additional indications for space use and activity zones (Vyncke et al. 2011). The results indicated clear differentiation between various zones: 1) a zone where the chemical trace was diffused, possibly due to its presence near a door opening in the northwestern corner; 2) a 'toilet' zone, where possibly a portable receptacle may have been placed to gather excrements in the opposite corner; 3) a hearth zone and possible food preparation area in the northeastern corner; 4) a location for a portable heating element such as a brazier in the middle of the room; and 5) a transit zone between different activity areas (Vyncke et al. 2011, p. 2290). Interestingly, in the southeastern corner of the room, a striking absence of chemical residues was noted, possibly suggesting that it could have been used for activities that did not leave any traceable chemical residues, for example as a sleeping area. This analysis indicates that all basic functions of a household were present in a single room. Whether or not this also suggests that other, if not all, rooms in the compound combined the same functions, thus compartmentalizing the overall structure even further into distinct spatial (and associated social) units, is hard to assess. It can likely be assumed that, in general, little spatial specialization would have existed and rooms likely had a multifunctional use. However, given the fact that an internal doorway existed between rooms $\mathrm{F}$ and $\mathrm{E}$ in the southern sequence, and rooms I and D are likely too small to be considered separate units, it can be assumed that at least the provisional identification of three different clusters belonging more or less together, can be maintained. Interestingly, the open spaces between the rooms yielded far larger amounts of material compared to inside, suggesting that either these were used more frequently, or that more refuse accumulated in these spaces, or a combination of both (Vyncke 2013, p. 273).

The overall settlement layout of Düzen Tepe appears unordered, with no clear pathways of movement or channelling of spaces through architecture. The resultant pattern of movement, vision and interaction throughout the settlement would therefore have been flexible and polycentric (Rob 2007, p. 90). A variety of building types have been identified, including many one-room structures, but also several multi-room complexes. The excavations at CYB show that one-room structures may have had a storage function, and that multi-room complexes could possibly be subdivided into several distinct units. As far as we can tell, such multi-room complexes with living spaces and storage rooms, possibly consisting of different house units but with shared walls and little 'depth' in room access, was typical for the settlement and its community. It should be noted, however, that only a fraction of the settlement has been excavated, and the CYB is likely the only domestic structure amongst the limited amount of excavated structures, giving us little comparable material to assess to what extent the finds at CYB are indeed typical for the settlement.

It would be nonsensical to assume that the entire settlement at Düzen Tepe was constituted of houses. Although only limited indications exist for social organization beyond the household level, some examples can be highlighted. A second major excavation conducted at Düzen Tepe was centred on a rectangular building $(19.5 \times 7.8 \mathrm{~m})$ located at the foot of Mount Zencirli (B on Figure 2). Through GPR it was discovered that it consisted of a sequence of three rooms (Figure 5). Upon excavation, it was found that, surprisingly, only for the central room (A) the southern wall covered (almost) the entire side, whereas it covered less than a third of the south side in room C, and room B is left completely open from that side (Figure 5). The architecture of the building is generally the same as the courtyard building, consisting of stone foundations providing the base for mudbrick walls, with a roof made from perishable materials. The most notable features of this excavation, however, were a series of small ovens, 
presumably bread ovens of the tandir-type, leading the building to be termed the 'Bakery'. Extensive ethnographic parallels for such tandır ovens have been attested in northeastern Anatolia (Köşklü 2006).

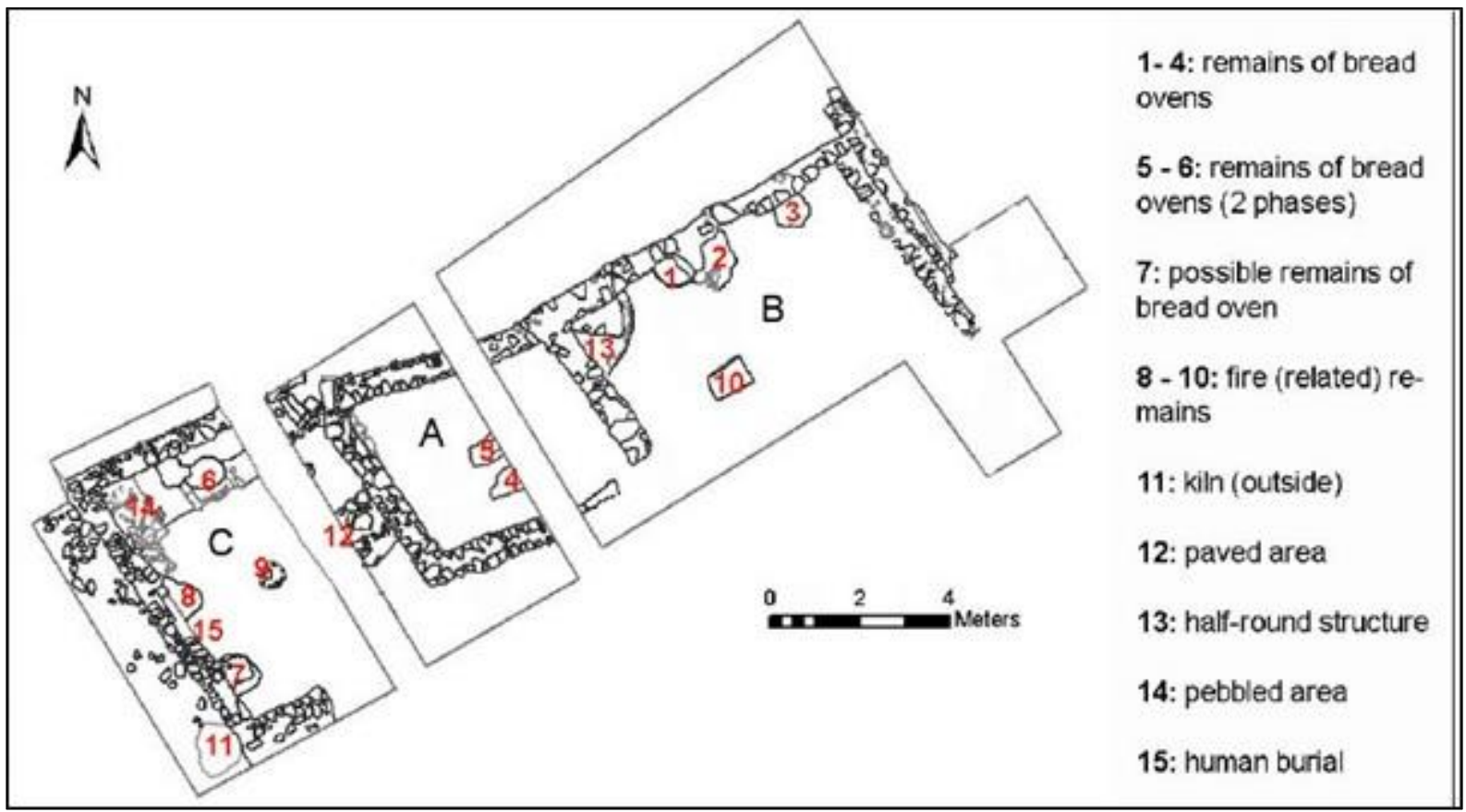

Figure 5: Plan of Bakery excavation (Vyncke 2013, p. 155).

The remains of the ovens consisted of a base of thin fired clay plaster up to $0.50 \mathrm{~m}$ in diameter. In some cases, the onset of a hemispherical upper structure with walls covered with a thin fired clay lining was present as well. The presence of the ovens likely explains the (partially) open southern side, which would have allowed the smoke to have escaped the building during use. In the northwestern corner of Room $\mathrm{C}$, an area covered with small limestone pebbles was discovered, much like the one in the courtyard building, possibly indicating the presence of a working surface here as well. The interpretation of the building as a bakery seems straightforward because of the presence of multiple bread ovens, as well as the discovery of four fragments of so-called 'Olynthus mills' or hopper rubbers, a type of fixed twopiece grinding installation used to grind grain into flour.

Some caveats need to be stated however. First, few indications exist for the lifespan of such an oven, nor for the duration of occupation of the structure. However, several structures appear to have been contemporaneous based on the stratigraphy. Moreover, the identification of overlaying sequential phases of ovens at a single location suggests that after the lifespan of one oven was expired, it could be rebuilt on the same spot, which makes the simultaneous use of different ovens at different spots within the building not infeasible. Even if this were to have been some kind of bakery, to what extent does this imply the presence of professional bakers? Alternatively, the ovens could be seen as specialized equipment that was available for a group of people, for example several households or families, to prepare food, as presumably this kind of infrastructure was infeasible to be present in every individual household. Furthermore, the identification as bread ovens is of course only tentative, and they may have been used to prepare various kinds of foods, suggesting rather a function as some sort of general communal kitchen rather than a bakery specifically (Vyncke 2013, p.157).

In addition to such features of communal organization, the construction of an elaborate fortification system indicates that, at least for essentialities such as communal safety and defence, sufficient incentives existed to initiate collective action measures, even if these escape our notice on any other instances. It can therefore be posited that, even if the main focus of social life likely remained at the household level, general functional collective action measures could be undertaken if the incentive to do so was perceived and acted upon by the community. These functional collective needs are mainly related to elements of subsistence, defence, production, etc.

How can we now interpret these data regarding social life and the nature of collective action at Düzen Tepe? As noted in the first part of this paper, collective action measures basically entail establishing 
cooperation between members of a community. In other words, finding consensus on appropriate strategies in face of certain problems or opportunities the community faced. Reviewing the literature on the emergence of social consensus, Baronchelli (2017) discerns two major modes of consensus-seeking strategies. First, those centred on (formal or informal) centralized institutions, for example authority, leadership, broadcasting (i.e. one-to-many distributors of information), centralized incentives for collective coordination, and closed information feedback loops (Baronchelli 2017, p. 2). When centralized institutions are not present in a given society, consensus comes either from the interaction between agents or from some predefined individual behaviour that is deemed 'desirable'. This 'spontaneous' emergence of consensus is then produced by self-interested and self-organizing individuals who are not intentionally aiming towards collective coordination. Its main mechanisms are: communication, (social) punishment of deviants, positive payoff externalities (i.e. pathways of development where once certain norms are established they persist), and conformity bias, all stimulating community formation dynamics (Baronchelli 2017, p. 3).

So far, no clear indications for centralized institutions have been attested at Düzen Tepe. Excavations conducted at the so-called 'Big Building' $(20 \times 25 \mathrm{~m})$ were planned with the aim of tackling a relatively large building compared to the average structure size at Düzen Tepe ( $\mathrm{C}$ on Figure 3), and which could therefore potentially have indicated some sort of public function. The walls of the building were, on average, $0.3 \mathrm{~m}$ wider compared to other structures at the site, as well as generally constructed with larger stone blocks. Two large limestone architectural fragments were found, one ashlar block and a cut block with levelled edge, which were the only attestations of architectural stone working at the site. Due to the large amount of stone fall, it was suggested that the building could have been constructed completely out of stone and had a tiled roof (Vyncke and Waelkens 2015, p. 163). To what extent the walls would actually have consisted of stone is hard to assess but at least the suggestion of a tiled roof can be doubted as it is based on only two pieces, which were likely misidentified and belonged rather to a large storage vessel.

Insofar as any indications for social organisation beyond the household level are present throughout the settlement, it pertains to a functional set of collective action measures, related to basic social needs such as subsistence or defence. The majority of the built environment of Düzen Tepe would therefore likely have operated on Rapoport's low level of meaning, focusing on mnemonic cues for appropriate use of spaces, primarily aimed at practical applications, rather than communicating identities, statuses and worldviews. This overall appreciation of the community is reflected in its material culture. As mentioned earlier, objects also inherently carry information regarding the spatial, temporal and social context or locale in which they were used. It has been noted that the pottery material of Düzen Tepe was first and foremost aimed at functional use, consisting of a basic process of least-effort resource exploitation, simple production technologies, production organisation centred on the household, a basic repertoire of functional shapes, multi-purpose fabric use, and locally-oriented subsistence exchange (Daems et al. 2017). Both from a technological and functional point of view, the material culture of Düzen Tepe displays a high degree of homogeneity and low diversity. Low material diversity has been considered characteristic for a non-centralized mode of consensus strategies. It induces conformist behaviour, also known as biased conformist transmission, referring to the tendency of people to copy or imitate ideas or behaviours of the majority of the group, thus facilitating intragroup cooperation as a way to reduce scalar stress in consensual decision making by establishing a degree of social cohesiveness (Hodder 1979; Johnson 1982).

The observed common orientation of buildings and spaces could point towards some form of coordination within the community that might be indicative of Rapoport's middle level of meaning (Smith 2007). However, it should also be noted that this need not be the result of (conscious) town planning but could, for example, also be indicative of adaptation to local circumstances including topography and climatological conditions such as prevalent directions of wind or sun (Vyncke and Waelkens 2015, p. 163).The fact that no central community features such as avenues, squares or other urban architecture are attested that could provide an additional explanation for the observed orientation seems to favour the latter explanation. In general, a village community like Düzen Tepe, consisting mainly of farmers in a smallholder system, would likely have been characterized by low degrees of social differentiation and inequality. The absence of clear indications for Rapoport's middle and high level meaning and worldviews need not mean that this was 'merely' a community of backward farmers 
whose only concern was working the land and trying to survive another day. It mainly means that we do not have enough suitable evidence to note this level of meaning in the available archaeological record. Let us now contrast these findings with data from the second case study, the nearby site of Sagalassos.

\section{Sagalassos}

Sagalassos was located about 1.8km from Düzen Tepe, on the mountain slopes north of the central parts of the Ağlasun valley (see Figure 1). The oldest signs of systematic habitation at the site in the form of a small-scale village community date from the late fifth century BCE onwards, based on a body of surface material collected during urban surveys conducted at the site. It can be suggested that, between the fifth and third centuries BCE, Sagalassos was likely a village community very much like that of Düzen Tepe, based on the high similarities in material culture, even though almost no stratigraphically secure contexts or structural remains have been attested for this period (Daems and Poblome 2017).

From the end of the third century BCE onwards, however, the archaeological record of Sagalassos changes with the development of an urban settlement fabric (Figure 6) (Talloen and Poblome 2016) and an associated new mode of material culture (Daems et al. In Press). This date provides a terminus ante quem for the urban transformation of Sagalassos, but, some indications for earlier developments exist. In 1996 and 2001, two parts of an inscription were found during excavations at the central square (agora) of the settlement. While the inscription would likely have been put on display on the square, it was incorporated in an associated building (the "Northeast Building") during a renovation phase dated to late antique times (Lavan 2013, p. 320-326). The inscription relates an agreement made in a decree on protecting the city against an internal rebellion, stating that those who seize the mountain fortress ( $a k r a)$, exile (parts of) the population, take up arms, or form an internally divisive faction, should be put to death by the dikastoi, thought to be some form of court magistrates (Vandorpe and Waelkens 2007). The decree was signed off by 24 archontes, likely the highest magistrates in the city. Based on stylistic arguments of the letter forms that were used, a general date between 333 and 200 BCE was suggested for the inscription. (Vandorpe 2000, p. 490; Eich et al. 2018, p. 24).

The inscription provides general provisions in the case of rebellion and the seizing of the mountain fortress by the rebels. Yet, it can also be suggested that the inscription was erected precisely to mark the end of a particular instance of such a rebellion, and ensure that it would not be repeated in the future. This would suggest that shortly before or during this period, a civil revolt took place involving Sagalassos and its fortress. The akra referred to in the text can likely be identified as the fortress on top of the mountain ridge right above Sagalassos (1885m a.s.l.), which was built to guard the relatively easy passage from the north across the ridge at that location. The oldest material found in recent test soundings conducted at the fortress could be dated to the second and first centuries BCE, somewhat later than the majority of the urban development at the town.

At the site itself, it does not come as a surprise that no evidence for associable struggles or destruction phases have been attested so far, given the general lack of stratigraphically secure contexts dated to this period. However, it can be suggested that the inscription would likely have been erected at the agora, the central focus of the community, where it would be most visible. Recent excavations at the Upper Agora indicated that the square was only constructed during the second century BCE, whereas previously a large clay quarry was present at this location (Talloen and Poblome 2016). If such a public square would have existed already in the third century, its location must be found elsewhere, but remains hitherto unknown. If the inscription did indeed refer to a specific event somewhere in the third century BCE, it would have preceded the first phase of urban development at Sagalassos. Given the mention of magistrates as the archontes and dikastai, this would mean that some sort of formalized and institutionalized political organisation had already developed, prior to the urban development of town. Dikastai are also mentioned in an inscription of nearby Termessos, dated to 281/280 BCE, presumably more or less the same period as, or preceding, the one from Sagalassos and written in similar letter forms (Vandorpe 2000, p. 490). The addition of a legislative section at the bottom of the inscription, specifying the change of punishment on theft occurring in the third century BCE, possibly associated with looting after a rebellion, from a fine of three minas to the death penalty, indicates that a formalised law code must have been present at Sagalassos even prior to these events as well. 


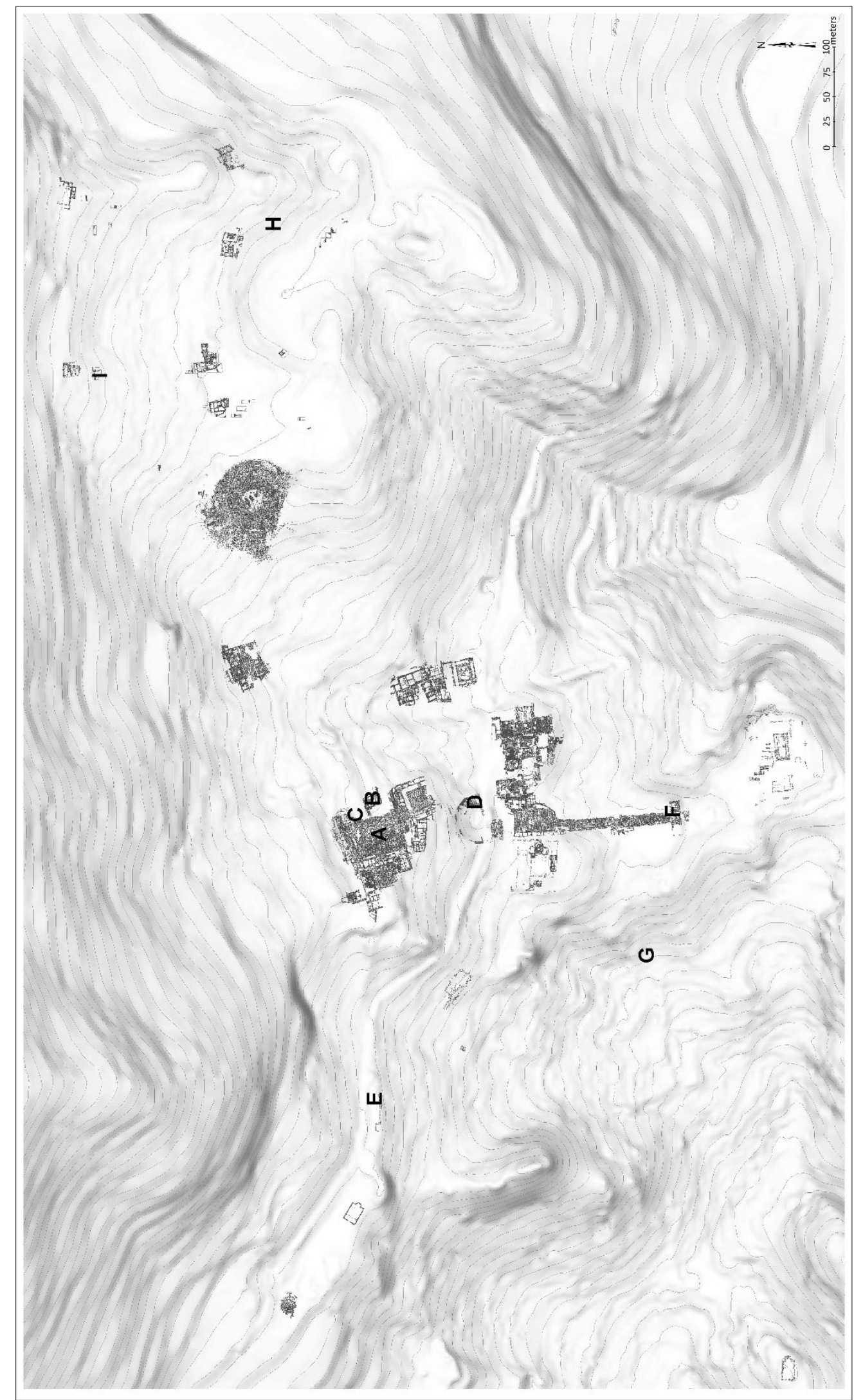

Figure 6: Excavated structures at Sagalassos, with indication of urban features dated to the third and second centuries BCE (A $=$ agora; $\mathrm{B}=$ presumed market building; $\mathrm{C}=$ terrace building; $\mathrm{D}=$ pottery kiln; $\mathrm{E} \& \mathrm{~F}=$ fortifications; $\mathrm{G} \& \mathrm{H}=$ necropoleis; $\mathrm{I}$ $=$ terrace wall and Hellenistic cremation burial). The outermost visible structures at every side more or less coincides with the maximum extent of the site. 
When discussing community formation and emergent urbanisation at Sagalassos at this time, we need to be aware of the limited chronological resolution of the material culture available to us. Few indications have been found for changes in material culture in-between the material associated with the earliest phase of a village community from the late fifth century BCE onwards, and the material associated with the urban transformation phase in the second century. Recent excavations have identified a handful of contexts associated with a small rubble wall underneath the slabs of the later agora, which yielded pottery material that could be dated to the third century BCE. ${ }^{1}$ This material could tentatively support the identification of an agora in the third century BCE, matching the date of the inscription, the events it describes, and the legal and political system it attests. Still, this would leave us with some chronological discrepancy between the development of a political community as attested in the inscription, and its material counterpart attested in the original urbanisation phase and its associated material culture. The underlying rationale would then be that a comparably close temporal sequence would not allow sufficient time for a widespread shift in material culture production processes and consumer tastes to be reflected in the material culture, or that little incentives for such changed were developed within the community. Two things can be noted. First, we can wonder to what extent the material culture reacts onto changes in socio-cultural and political fabrics in a comparably rapid fashion. For the urban transformation phase it can be noted that the shift in associated material culture does indeed appear quite rapid and radical, opening up at least a window of opportunity for such a scenario. Second, if such shifts can indeed potentially appear quite rapidly, would there be any reason why an urban transformation would have been more readily reflected in the material culture compared to a political transformation? Finally, it leaves the matter of explaining why this 'lag' time' (give or take one or two generations) between the emergence of a political community, and an associated transformation of the settlement lay-out from a village to an urban community even existed.

To this end, let us take a look at what the urban transformation of Sagalassos actually means with regard to the actual social activities, interactions and practices shaping the community that used these places on a day-to-day basis. The first phase of urban development at Sagalassos consisted of the construction of an agora around $200 \mathrm{BCE}$ (or slightly earlier, cfr. supra) of about $25 \mathrm{~m}$ by $40 \mathrm{~m}$ (Figure 7). One generation later, a building that has been tentatively identified as a Market Building was erected along its eastern side. The monumentalization of the area surrounding the agora was extended in the second half of the century, with the construction of a monumental building of unknown function at the northeastern side, and a monumental terrace wall. Combined with a number of notable changes elsewhere in town, including the development of a spatially demarcated production quarter in the southern parts, the demarcation of the inhabited zone with spatially distinguished necropoleis, and the construction of a fortification wall towards the end of the century, the second century BCE saw a markedly radical transformation of the urban townscape. Rather than focusing on a detailed relating of the construction features and sequences, it should be stressed that the central element of this process was not necessarily the monumental nature of this transformation process, but rather the societal function it represented and fulfilled.

Monumental public buildings represented a clear and circumscribed arena of public life. Whereas, at Düzen Tepe, the household was likely the main locus of the community, social life at Sagalassos would have been increasingly drawn into these focal points, thus creating a well-defined spatial container for social interactions to be oriented towards. As a result, a wholly new range of interactions would have emerged and developed within these newly defined places, supplementing those within the context of the household - which possibly would have continued without major changes, even though no household contexts from this period are known to us. Think for example of public voting procedures for selection of the public officials, which would likely have taken place at the agora as the political, social and economic heart of the community.

\footnotetext{
${ }^{1}$ Studies conducted by the author in 2019 , results are in preparation.
} 


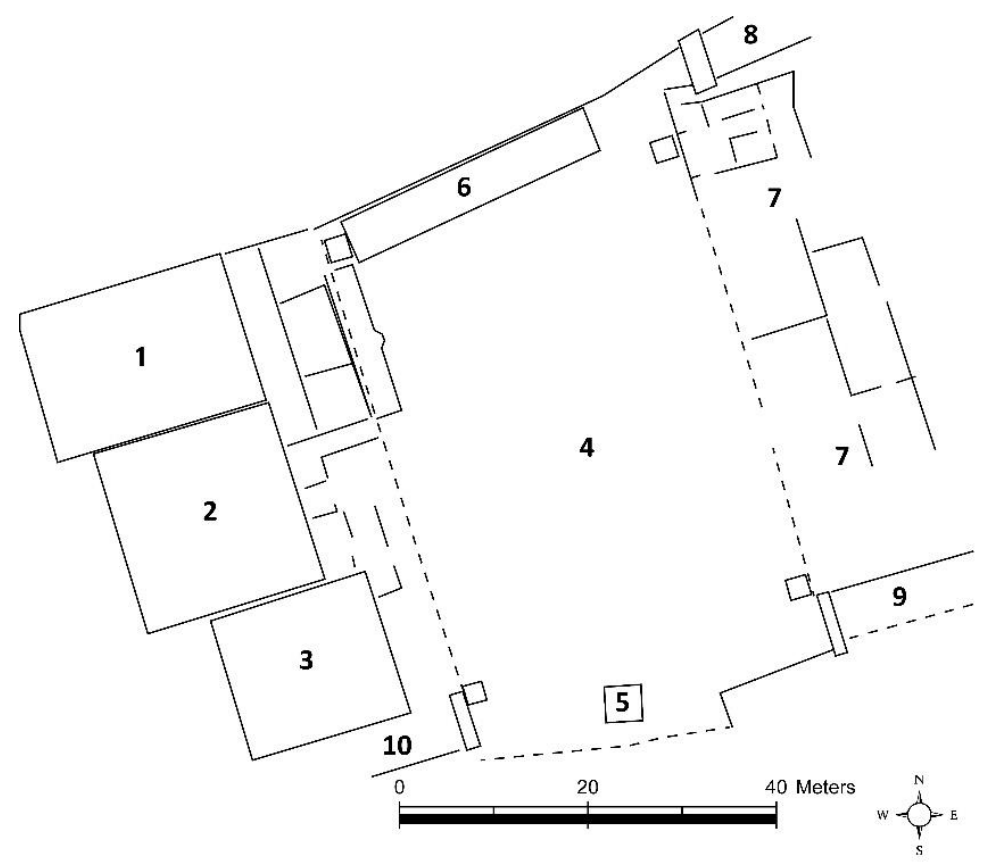

Figure 7: Schematic plan of the agora and associated buildings. (1) Basilica, (2) Bouleuterion, (3) Prytaneion, (4) Upper Agora, (5) Tychaion, (6) Antonine Nymphaeum, (7) Market Building, (8) Northeast Street, (9) Southeast Street, (10) Southwest Street.

It is not coincidental that the observed monumentalization of the town started in and spread out from the agora. Through intensive use of this new focus of public life, the locale centred on this location would have likely been extended to include closely associated areas as well. The erection of the market building can, for example, be considered as a partial specialization within the economic sphere of life, where specific parts of the multi-purpose functionality from the agora were shifted towards a more specialized locale.

These market buildings were colonnaded porticoes (stoai) with additional substructures and a number of rooms below and behind the colonnades, generally located at the agora (Köse 2005). They are attested at numerous towns across Anatolia, such as Pergamon, Miletos, Priene, Magnesia, Herakleia, Xanthos, Selge, and Aspendos, and elsewhere in the Hellenistic world, mainly from early Hellenistic times onwards, and often combined storage facilities with spaces for commercial exchange (shops and workshops). It provided a circumscribed location where frequently repeated actions, such as exchanging goods, could be streamlined through the reduction of uncertainty and 'noise' in communications by offering a fixed avenue of interaction (Fletcher 1995, p. 143-144). Considered from a neo-institutional point of view, such formal settings reduce investment in information gathering by offering the certainty of encountering a sufficient number of participating buyers and sellers - at least in periodic attendance - to underwrite system development (North 1990).

Next to this strictly functional aspect, monumental urban architecture also communicates a number of messages, including the ability of the community to carry out elaborate construction projects, demonstrate power, and transform disorder into order. This last element pertains to the shift from bottom-up dynamics, movement and interaction centred on the households towards centralized structures of order and channelled movement, centred on clearly defined and visible public spaces. The redefinition of control over social, economic and political spheres of life towards the community level provides 'official' messages of social behaviour and worldviews to induce conformation to collective societal needs, desirables and habits (Smith 2007, p. 35). It is not always clear who the actors behind these processes were, whether a (small) elite attempted to obtain control over the wider community and impose its worldview, or whether the community as a whole drove these dynamics.

The emergence of circumscribed public spaces of social life thus entails a shift from decentralized or spontaneous consensus-seeking mechanisms, such as at Düzen Tepe, partially expressed through material culture, towards an institutionalisation of consensus-stimulating mechanisms resulting in centralized control over this official message and the values it expressed. As a result, there would have been less need for an equally excessive degree of social conformity over material culture. This might 
then allow for increased material variability to be observed due to the different stakeholders within the productive process to have more freedom for deviant incentives in the complex negotiations of meaning.

The urban transformation of Sagalassos in the late third and early second centuries BCE was associated with a marked territorial increase, extending from its original catchment covering the central parts of the Ağlasun valley, to include an area stretching from the Kestros river in the east to Lake Burdur in the west (Figure 1) (Daems and Poblome 2016; Waelkens 2004). At this point, a pathway of development was initiated at Sagalassos, which saw it develop into a prominent local, and regional urban hub from Hellenistic times onwards, continuing well into Roman imperial times. Düzen Tepe, on the other hand, was abandoned during the second century BCE, roughly at the time when developments at Sagalassos started to take off, with the community of the former possibly moving to Sagalassos.

Several possible scenarios exist, including a fully endogenous development born out of local system dynamics, where the expansion of Sagalassos overshadowed Düzen Tepe or a synoikismos ${ }^{2}$ event resulted in the merging of Sagalassos and Düzen Tepe. While either a fully endogenous or a one-sided centrally-induced synoikismos cannot be excluded, it has been suggested that the mediating role of macro-scale polities, extending economic and political policies aimed at collaborating with local partners and structures of administration to supplement the central and provincial bureaucracy, could well have stimulated - if not initiated - such a development (Daems and Poblome 2016). In this scenario, local communities such as Sagalassos might have reacted upon such external stimuli to initiate a transformation from village community into an urban system hub, necessary to act as a reliable local partner, both in an economic and political/strategic sense. Population increase and aggregation associated with such an event would then have provided the necessary base to kick-start social dynamics at the site onto a whole new level. Given that the Seleucids ruled over large parts of Anatolia, including the area of Sagalassos, at the time of these events, they can be considered prime potential candidates to be associated with these local developments.

The following scenario can be suggested. Upon gaining control over Anatolia, the Seleucids sought to extend centralized structures of control, focused mainly on surviving imperial and provincial administrative structures left by the Persian empire, with a local dimension (Aperghis 2004). The Seleucids are known for having been highly active in city foundations (Cohen 1978). However, rather than founding a new city ab novo, they chose here to seek out an existing community to act as a local partner. The reason behind this choice is unclear and might remain in the murky realm of historical contingency, as historical pathways of development may at times be constrained and developed along (semi-)random circumstances and decisions. Possibly a similar twist of fate decided on why Sagalassos ended up as primary centre, whereas Düzen Tepe dwindled out of existence.

It can be noted that Sagalassos held certain locational advantages over Düzen Tepe. The strategic position of the latter on top of an elevated plateau would have had certain military advantages, however, at the same time it also markedly limited its ability to exploit the economic potential of the environment due to comparably difficult access routes. Moreover, the limited extent of the plateau also markedly limited the growth potential of the site. Sagalassos, on the other hand, while still being strategically positioned on the mountain flanks, had far easier access to the lower valleys and disposed of a relatively extensive area for potential extension. Moreover, its extensive access to water sources would have offered a comparative advantage for housing an extensive settlement as well. It can be noted that the exact reason for the eventual divergent development need not necessarily be very notable or profound. Given the overall nature of human societies as complex societies, societal dynamics are highly sensitive to initial conditions, where even very small differences can lead to widely divergent trajectories of development (Bintliff 1997).

In analogy with ecosystems, changing external circumstances (situational events) can create wholly new niches for species (communities) to proliferate and develop. Whatever the underlying reason(s), once the stimuli associated with this initial situational event were produced and a new niche for development opened up, local communities still had to perceive the opportunity, interpret its potential, and react

\footnotetext{
2 The term synoikismos denotes the merging of two separate entities into a single community, with either one population being subsumed into the site and community of the other, or the foundation of a wholly new community located at a distinct new place.
} 
accordingly - following the signal detection, information-processing, and problem-solving loop outlined earlier - to exploit this newly-founded niche. None of these steps should be taken for granted, and indeed the divergent development between Sagalassos and Düzen Tepe could have been due to different perceptions or responses to such opportunities. The effectiveness of collective action measures to stimulate community-level social consensus and induce more efficient responses to such opportunities would to a large degree have influenced this pathway of development as well. The limitations of the archaeological record of Sagalassos at this period of time inhibits further comparison for now.

The situational event created by the synergy between (Seleucid) policies and local strategies would likely have had a significant socio-political impact, with the introduction of a limited number of 'spokespersons' to govern local affairs and conduct communication with higher levels of organizational structures. These would likely have been modelled on the templates available to both the Seleucids and the local population, i.e. a set of public officials with clearly defined powers and responsibilities (Ma 1999, 2013). The mention of such officials in the inscription mentioned earlier could then be linked to such a foundational event. The fact that the inscription was drafted in bad Greek and that none of the 24 named archontes had a Greek name, indicates that the process should be considered a local translation of such an overall template, rather than the outright imposition of Greek-oriented modes of cultural and social organisation.

At the same time, a certain influx of resources, (physical) capital and knowledge (or human capital) may have been initiated, to provide the necessary groundwork for inducing the urban transformation of the settlement as well. The marked extension of the territory to include the fertile Burdur plain would definitely have allowed a significant increase in potential energy and resources to become available to the community at Sagalassos, supporting the observed developments at the site and the increased energy requirements associated with building and maintaining monumental public architecture and increasing production outputs. However, some caveats should be stated. Even if the potential avenues of exploitation would have been made available, it would likely have taken some time before these were sufficiently initiated for this potential to be tapped and capital would to start flow towards Sagalassos. This addition of external capital and knowhow to local networks of knowledge, would explain why a community - which up to then operated in a very much locally embedded network, oriented towards local environmental circumstances and niches within a local pathway of development - suddenly initiated a marked transformation of settlement fabric, material culture and socio-political organisation in response to a newly-developed potential niche of development.

Even if the urbanization of the town was initiated at more or less the same time, this would explain the observed lag-time between the genesis of a political structure, and the realization of the transformation in urban infrastructure, given the slower replication rate and higher inertia of the material environment compared to rapidly changing dynamics of social interaction (Fletcher 1995, p. 16). Moreover, it would explain why the transformation, once induced, stretched into a trajectory of development spanning the majority of the century (and even continuing well into late Hellenistic and Roman imperial times) as after the initial investment, it relied on the development of avenues of energy exploitation, channelling the exploited capital of the wider territory towards the centre.

We can also wonder to what extent the full potential of this territory could have been exploited, given that even in Roman imperial times certain parts of the territory were only loosely integrated in the overarching economic and administrative structures (Kaptijn et al. 2013). The asymmetric location of Sagalassos compared to its surrounding territory (see Figure 1) could have inhibited the full development of regular structures of exploitation, relying instead on a system of more of irregular and episodic structures, especially for the western part of the territory, as Sagalassos would have more naturally focused on the eastern areas centred on the Ağlasun and Çanaklı valleys.

We have no way of finding out which precise actors within the community initiated the local shift in strategies to move towards the newly-available niche of opportunity. Given the present knowledge, we can only wonder to what extent a certain degree of social inequality was already present in these communities, which would allow existing leaders within the community to react to new opportunities, or whether one or more clever primus inter pares was able to recognize the potential benefits of these new circumstances to gain a prominent position within the community. We do see, however, who eventually claimed the available space. The initiation of a political class of public officials during the third century BCE would provide the necessary foundations for influential members of community to 
start proliferating. The transformation phase at Sagalassos was accompanied by the development of a socio-political elite, which started to manifest itself through strategies of self-representation and symbolic expression of identity. These strategies would increasingly come to be expressed through the development of public arenas of social life, most notably the agora, which came to be gradually furbished with honorary monuments and inscriptions, especially towards the late Hellenistic period (Talloen and Poblome 2016, p. 121-122).

Of course, the observed full-scale transformation of the community cannot be fully reduced to an elitedriven development. Undoubtedly, various social groups, households, grassroots initiatives and individuals would have markedly affected this development as well. For example, a variety of actors, ranging from producers and traders to consumers, well beyond the elite, would have been involved in the transformation of material culture associated with the urbanization of the settlement itself. A newlydeveloped social elite could have induced the transition towards a wholesale transformation of the social, political, economic and architectural fabric of the town, but it would be sustained only if their ambitions were supported by large parts of city-dwellers throughout all layers and groups within the community (Smith 2003, p. 24-28).

\section{Conclusions}

In the end, the trajectory of development presented here is only one possible scenario, given the archaeological and historical evidence available. More evidence and studies will be needed, including also data from a wider regional perspective, to transform parts of this hypothesis into conclusions. Still, this paper has shown how local processes of community formation and urbanisation can be interpreted within an overarching context of historical development.

The process started from the presence of small-scale village communities at Düzen Tepe and Sagalassos from the late fifth century BCE onwards. It should be stressed that there is no need to interpret these village communities from a modernist or Eurocentric perspective, labelling them a simple society in the sense of 'rudimentary or 'old-fashioned' (Vyncke and Waelkens 2015). These people were part of a traditional community, who lived and did certain things in a way that came naturally to them, likely in more or less the same ways as their parents had done before them. However, we should remember that this type of living was successful for a long time. These kinds of communities are often well aware of the landscape surrounding them, conscious of its possibilities and limitations, and use these to carve out a niche for themselves to live their lives and maintain their community. Their way of life effectively constituted a local basin of attraction, adapted to match local circumstances and landscapes. It was suggested that these village communities operated within a local historical pathway of development, centred on basic needs such as subsistence, habitation, defence, production, exchange, etc., within functionally-oriented contexts of engagement and social life, conducted mainly within the framework of the household and supplemented with a limited degree of (functional) inter-household or communitylevel organisation and collective action measures.

In the long run, such an approach would likely have continued to be successful. At some point however, circumstances changed. The introduction of new situational events - possibly induced by outside stimuli and policies - created a new playing field, changing the rules of the game and pushing communities towards a new potential basin of attraction. This way, interactions between actors on different scales intensified processes of community formation and development of organizational complexity. Whether the community at Düzen Tepe was unable to cope with these changes, or whether they did not see the need to react, or simply did not want to, in the end the result remains the same. Sagalassos made the leap and took the mantle of prime local and regional centre from Hellenistic times onwards.

The transformation of the social, political, economic and architectural fabric of Sagalassos saw the extension of this local template of community organisation, with symbolic strategies of selfrepresentation and identity, centred on monumental public spaces and buildings, providing a locale for a completely new set of dynamics and practices, reflected in a new mode of material culture. It constituted the supplementation of low level meaning of mnemonic cues and practical use, with middle level meaning communicating status and identity. This transformation effectively induced a change in local basins of attraction, transforming the village community of Sagalassos into an urban hub, which started to increasingly pull in flows of energy, resources and information from the third and second centuries BCE onwards. At the same time, the settlement at Dïzen Tepe was abandoned during the second century BCE, with its population possibly moving to Sagalassos, and the original community 
forgotten between the folds of time. As the saying goes "history is written by the victors", and the less fortunate tend to be forgotten, that is, until maybe someday an archaeologist walks by....

\section{Acknowledgements}

The research for this paper was funded through a fellowship by the Research Foundation Flanders, and has further been supported by the Belgian Programme on Interuniversity Poles of Attraction, the Research Fund of the University of Leuven, and the Academic Foundation Leuven. The author has been part of the Sagalassos Archaeological Research Project, originally directed by Marc Waelkens and since 2014 under directorship of Jeroen Poblome (both KU Leuven). The author wishes to thank Bas Beaujean for his help with some of the figures, Kim Vyncke and Hannelore Vanhaverbeke, who coordinated the excavations at the site of Düzen Tepe, and Peter Talloen who coordinated the excavations at the Upper Agora of Sagalassos. Gratitude is also due to Jeroen Poblome, John Bintliff, Sander van der Leeuw, Philip Van Peer, Christopher Ratté, and Katelijn Vandorpe for their comments and feedback on earlier versions of this text.

\section{References}

Aperghis, G., 2004. The Seleukid royal economy: the finances and financial administration of the Seleukid empire. Cambridge University Press, Cambridge

Auban, J., Martin, A., Barton C., 2013. Complex Systems, Social Networks, and the evolution of Social Complexity in the East of Spain from the Neolithic to Pre-Roman Times. In: Berrocal, M., Sanjuán, L., Gilman, A. (Eds.), The Prehistory of Iberia: Debating Early Social Stratification and the State. Routledge, New York, pp. 53-73.

Axelrod, R., 1984. The evolution of cooperation. Basic Books, New York.

Baronchelli, A., 2017. The Emergence of Consensus: A Primer. Retrieved from http://arxiv.org/abs/1704.07767

Bentley, A., and Maschner, H. 2003. Complex Systems and Archaeology. Utah University Press, Salt Lake City.

Bettencourt, L., 2013. The Origins of Scaling in Cities. Science 340(6139), 1438-1441.

Bintliff, J., 1997. Catastrophe, chaos and complexity: The death, decay and rebirth of towns from antiquity to today. The Journal of European Archaeology 5, 67-90.

Blanton, R. and Fargher, L., 2016. How Humans Cooperate: Confronting the Challenges of Collective Action. University Press of Colorado, Boulder.

Blau, P., 1964. Exchange and Power in Social Life. Transaction Publishers, London.

Cabrera, D., Colosi, L., Lobdell, L., 2008. Systems thinking. Evaluation and Program Planning 31(3), 299-310.

Canuto, M., and Yaeger, J., 2000. Archaeology of Communities: A New World Perspective. Routledge, New York.

Castellani, B. and Hafferty, F., 2009. Sociology and Complexity Science: A New Field of Inquiry. Springer, Heidelberg.

Childe, G., 1950. The Urban Revolution. Town Planning Review 21, 3-17.

Cioffi-Revilla, C., 2005. A Canonical Theory of Origins and Development of Social Complexity. The Journal of Mathematical Sociology 29(2), 133-153.

Clarke, D., 1968. Analytical archaeology. Methuen \& Co Ltd, London.

Cleymans, S., Daems, D., Broothaers, N., In Preparation. Sustaining People. Reassessing carrying capacity through the socio-ecological metabolism of the ancient community at Düzen Tepe, SW Turkey. 
Cohen, G., 1978. The Seleucid colonies : studies in founding, administration and organization. Steiner, Wiesbaden.

Cohen, A., 1985. The Symbolic Construction of Community. Horwood, Chichester.

Cowgill, G., 2004. Origins And Development of Urbanism: Archaeological Perspectives. Annual Review of Anthropology 33, 525-549.

Daems, D., and Poblome, J., 2016. Adaptive cycles in communities and landscapes. The case of Sagalassos and Düzen Tepe during the Classical/Hellenistic period. Archaeological Review of Cambridge 31(2), 91-107.

Daems, D., and Poblome, J., 2017. The Pottery of Achaemenid Sagalassos: An Overview. Herom 6(1), 49-62.

Daems D., Braekmans, D, Poblome, J., 2017. Late Achaemenid and Early Hellenistic Pisidian Material Culture from Düzen Tepe (SW Anatolia). Herom, 6(1), 11-48.

Daems, D, van Der Enden, M., Talloen, P., Poblome, J., In Press. The mid Hellenistic Pottery Repertoire made at Sagalassos, SW Anatolia. Conference proceedings of the second conference of the International Association for Research on Pottery of the Hellenistic Period (IARPOTHP), Lyon, November 2015.

Dubreuil, B., 2010. Human Evolution and the Origins of Hierarchies: The State of Nature. Cambridge University Press, Cambridge.

Dunbar, R., 1993. Co-evolution of Neocortex Size, Group Size and Language in Humans. Behavioral and Brain Sciences 16(4), 681-735.

Eich, A., Eich, P. and Eck, W., 2018., Die Inschriften von Sagalassos, I. Habelt, Bonn.

Feld, S. and Basso, K., 1996. Senses of Place. School of American Research Press, Santa Fe.

Fisher, K. and Creekmore, A., 2014. Making Ancient Cities: New Perspectives on the Production of Urban Places. In: Creekmore, A. and Fisher, K. (Eds.), Making Ancient Cities: Space and Place in Early Urban Societies. Cambridge University Press, New York, pp. 1-31.

Fletcher, R., 1995. The limits of settlement growth : a theoretical outline. Cambridge University Press, Cambridge.

Freeberg, T., Dunbar, R., Ord, T., 2012. Social complexity as a proximate and ultimate factor in communicative complexity. Philosophical Transactions of the Royal Society of Biology: Biological Sciences 367, 1785-1801.

Gerritsen, F., 2004. Archaeological Perspectives on Local Communities. In: Bintliff, J. (Ed.), A Companion to Archaeology. Blackwell Publishing, Oxford, pp. 141-154.

Giddens, A., 1986. The Constitution of Society: Outline of the Theory of Structuration. University of California Press, Berkeley.

Gladwell, M., 2000. The Tipping Point: How Little Things Can Make a Big Difference. Abacus, London.

Hidalgo, C., 2015. Why Information Grows: The Evolution of Order, from Atoms to Economies. Basic Books, New York.

Hodder, I., 1979. Social and economic stress and material culture patterning. American Antiquity 44, 446-454.

Johnson, G., 1982. Organisational Structure and Scalar Stress. In: Renfrew, C., Rowlands, R., Seagraves, B. (Eds.), Theory and Explanation in Archaeology. Academic Press, New York, pp. 389412. 
Kaptijn, E., Poblome, J., Vanhaverbeke, H., Bakker, J., Waelkens, M., 2013. Societal changes in the Hellenistic, Roman and early Byzantine periods. Results from the Sagalassos Territorial Archaeological Survey 2008 (southwest Turkey). Anatolian Studies 63, 75-95.

Kohler, T., Van Buskirk, S., Ruscavage-Barz, S., 2004. Vessels and villages: evidence for conformist transmission in early village aggregations on the Pajarito Plateau, New Mexico. Journal of Anthropological Archaeology 23(1), 100-118.

Kohring, S., Odriozola, C., Hurtado, V., 2007. Materialising 'complex' social relationships: Technology, production and consumption in a Copper Age Community. In: Kohring, S. and WynneJones, S. (Eds.), Socialising Complexity: Structure, Interaction and Power in Archaeological Discourse. Oxbow Books, Oxford, pp. 100-117.

Kolb, M. and Snead, J., 1997. It's a Small World after All: Comparative Analyses of Community Organization in Archaeology. American Antiquity 62(4), 609-628.

Köse, V., 2005. The origin and development of market-buildings in Hellenistic and Roman Asia Minor, In: Mitchell, S. and Katsari, C. (Eds.), Patterns in the Economy of Roman Asia Minor. Classical Press of Wales, Swansea, pp. 139-166.

Köşklü, Z., 2006. Household clay pit ovens in Northeast Anatolia. In: Takaoğlu, T. (Ed.), Ethnoarchaeological investigations in rural Anatolia. Volume 3. Ege Yayınları, Istanbul, pp. 45-57.

Lavan, L., 2013. The agorai of Sagalassos in late antiquity: An interpretive study. In: Lavan, L. and Mulryan, M. (Eds.), Field Methods and Post-Excavation Techniques in Late Antique Archaeology (Late Antique Archaeology 9). Brill, Leuven, pp. 289-353.

Low, S. and Lawrence-Zúñiga, D., 2003. The anthropology of space and place: locating culture. Blackwell, Oxford.

Lucas, G., 2012. Understanding the Archaeological Record. Cambridge University Press, Cambridge.

Ma, J., 1999. Antiochus III and the cities of Western Asia Minor. Oxford University Press, Oxford.

Ma, J., 2013. Hellenistic Empires. In: Bang, P. and W. Scheidel (Eds.), The Oxford Handbook of the State in the Ancient Near East and Mediterranean. Oxford University Press, Oxford.

Marston, J., 2015. Modeling Resilience and Sustainability in Ancient Agricultural Systems. Journal of Ethnobiology 35(3), 585-605.

Mitchell, M., 2009. Complexity: A Guided Tour. Oxford University Press, Oxford.

Nelson, M., Hegmon, M., Kulow, S., Peeples, M., Kintigh, K., Kinzig, A., 2011. Resisting Diversity: a Long-Term Archaeological Study. Ecology and Society 16(1).

North, D., 1990. Institutions, Institutional Change and Economic Performance. Cambridge University Press, Cambridge.

Ortman, S. and Coffey, G., 2015. Universal Scaling: Evidence from Village-Level Societies. Santa Fe Working Paper, 1-40.

Ortman, S., Davis, K., Lobo, J., Smith, M., Bettencourt, L., Trumbo, A., 2016. Settlement scaling and economic change in the Central Andes. Journal of Archaeological Science 73, 94-106.

Ortman, S., Cabaniss, A., Sturm, J., Bettencourt, L., 2015. Settlement Scaling and Increasing Returns in an Ancient Society. Science Advances 1(1).

Page, S., 2010. Diversity and Complexity. Princeton University Press, Princeton.

Parsons, T., 1977. Social systems and the evolution of action theory. Free Press, Glencoe. 
Rapoport, A., 1988. Levels of meaning in the built environment. In: Poyatos, F. (Ed.), Cross-cultural perspectives in nonverbal communication. C. J. Hogrefe, Toronto, pp. 317-336.

Rapoport, A., 1990. The meaning of the built environment: A nonverbal communication approach. University of Arizona Press, Tucson.

Rapoport, A., 2006. Archaeology and environment-behavior studies. In: Ashmore, W., Dobres, M., Nelson, S., Rosen, A. (Eds.), Integrating the diversity of twenty-first-century anthropology: The life and intellectual legacies of Susan Kent. American Anthropological Association, Washington DC, pp. 59-70.

Robb, J., 2007. The Early Mediterranean Village: Agency, Material Culture, and Social Change in Neolithic Italy. Cambridge University Press, Cambridge.

Rodman, M., 1992. Empowering Place: Multilocality and Multivocality. American Anthropologist 94(3), 640-656.

Sanderson, S., 1999. Social transformations: a general theory of historical development. Rowman \& Littlefield, Totowa.

Service, E. , 1962. Primitive social organization: an evolutionary perspective. Random House, New York.

Smejda, L. and Baumanova, M., 2015. Conceptual Crossroads: Community and Society in Prehistory. In: Kristiansen, K., Smejda, L., Turek, J. (Eds.), Paradigm Found: Archaeological Theory - Present, Past and Future. Essays in Honour of Evzen Neustupny. Oxbow Books, Oxford, pp. 47-60.

Smith, A., 2003. The Political Landscape: Constellations of Authority in Early Complex Polities. University of California Press, Berkeley.

Smith, M., 2007. Form and Meaning in the Earliest Cities: A New Approach to Ancient Urban Planning. Journal of Planning History 6(1), 3-47.

Smith, M., 2019. Energized Crowding and the Generative Role of Settlement Aggregation and Urbanization. In: Gyucha, A. (Ed.), Coming Together: Comparative Approaches to Population Aggregation and Early Urbanization. State University of New York Press, Albany, pp. 37-58.

Steidl, C., 2018. Community Formation in Iron Age Ionia: Experience and Practice in Comparative Perspective. Unpublished Ph.D. Diss. Brown University.

Southall, A., 1973. Urban anthropology: cross-cultural studies of urbanization. Oxford University Press, New York.

Talloen, P. and Poblome, J., 2016. The 2014 and 2015 control excavations on and around the Upper Agora of Sagalassos: The structural remains and general phasing. Anatolica 42, 111-150.

Turner, J., 2003. Human institutions: a theory of societal evolution. Rowman \& Littlefield, Totowa.

Vandorpe, K. and Waelkens, M., 2007. Protecting Sagalassos' fortress (akra) and watchtowers: an early Hellenistic inscription. Ancient Society 37, 121-139.

Vandorpe, K., 2000. Negotiators' Laws from Rebellious Sagalassos in an Early Hellenistic Inscription. In: Waelkens, M. and Loots, L. (Eds.), Sagalassos V: report on the survey and excavation campaigns of 1996 and 1997. Leuven University Press, Leuven, pp. 489-507.

Varien, M., and Potter, J., 2008. The Social Construction of Communities: Agency, Structure, and Identity in the Prehispanic Southwest. Rowman, Altamira.

Vyncke, K. and Waelkens, M., 2015. The Classical/Hellenistic Courtyard Building at Düzen Tepe (SW Turkey). Hypotheses on the Factors Influencing House Form and Functions. In: Di Castro, A., Hope, C., Parr, B. (Eds.), Housing and habitat in the ancient Mediterranean: cultural and environmental responses. Babesch Supplements 26. Peeters, Leuven, pp. 161-169. 
Vyncke, K., 2013. Düzen Tepe. The Potential of Contextual Analysis and Functional Space Analysis by means of an Interdisciplinary Archaeological and Archaeometric Research at a Classical-Hellenistic Site. Unpublished Ph.D. Diss., KU Leuven.

Vyncke, K., Degryse, P., Vassilieva, E., Waelkens, M., 2011. Identifying domestic functional areas. Chemical analysis of floor sediments at the Classical-Hellenistic settlement at Düzen Tepe (SW Turkey). Journal of Archaeological Science 38(9), 2274-2292.

Waelkens, M., 2004. Ein Blick von der Ferne: Seleukiden und Attaliden in Pisidien. Istanbuler Mitteilungen 54, 435-471. 